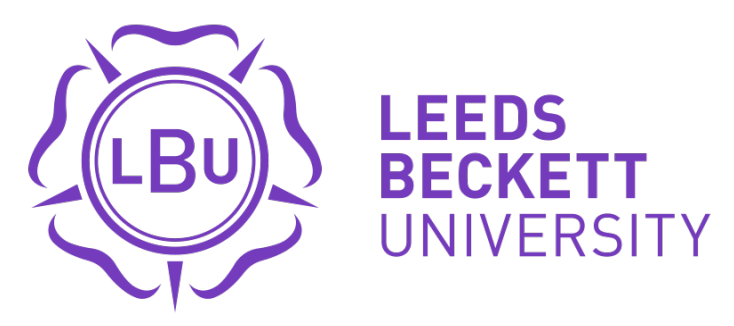

Citation:

Shukhobodskiy, AA and Colantuono, G (2020) RED WoLF: Combining a battery and thermal energy reservoirs as a hybrid storage system. Applied Energy, 274. ISSN 0306-2619 DOI: https://doi.org/10.1016/j.apenergy.2020.115209

Link to Leeds Beckett Repository record:

https://eprints.leedsbeckett.ac.uk/id/eprint/6867/

Document Version:

Article (Accepted Version)

Creative Commons: Attribution-Noncommercial-No Derivative Works 4.0

The aim of the Leeds Beckett Repository is to provide open access to our research, as required by funder policies and permitted by publishers and copyright law.

The Leeds Beckett repository holds a wide range of publications, each of which has been checked for copyright and the relevant embargo period has been applied by the Research Services team.

We operate on a standard take-down policy. If you are the author or publisher of an output and you would like it removed from the repository, please contact us and we will investigate on a case-by-case basis.

Each thesis in the repository has been cleared where necessary by the author for third party copyright. If you would like a thesis to be removed from the repository or believe there is an issue with copyright, please contact us on openaccess@leedsbeckett.ac.uk and we will investigate on a case-by-case basis. 


\title{
RED WoLF: Combining a Battery and Thermal Energy Reservoirs as a Hybrid Storage System
}

\author{
Alexander Alexandrovich Shukhobodskiy ${ }^{1 *}$, Giuseppe Colantuono ${ }^{1 * *}$, \\ 1, School of Built Environment, Engineering and Computing, Leeds Beckett University, Leeds, UK, LS1 3HE
}

\begin{abstract}
Energy consumption of households is not evenly distributed. To satisfy peak demand, additional $\mathrm{CO}_{2}$ intensive generators are turned on when demand peaks. To avoid peak demand from dwellings, the RED WoLF (Rethink Electricity Distribution Without Load Following) hybrid storage system is proposed, consisting of batteries, storage heaters and a water cylinder. This aims at avoiding the use of these peak generators and integrating a higher share of renewables on the Power Grid. This system is planned to be tested in 100 houses distributed in 6 pilot sites in Great Britain, Ireland and France, which are currently undergoing construction or refurbishment. This study presents the theoretical model of the controlling algorithm, which enables the uptake of Grid electricity only when $\mathrm{CO}_{2}$ intensity is below a dynamically computed threshold. The algorithm is tested in computer simulations over the four seasons with varying size of batteries and photovoltaic arrays. Results show how RED WoLF algorithm satisfies households demands while, at the same time, successfully avoiding domestic peak demand, with a significant drop of $\mathrm{CO}_{2}$ emissions. This is achieved by both increasing photovoltaic self-consumption and uptake of low carbon Grid energy. For example, with a $7 \mathrm{kWh}$ battery and a $4 \mathrm{~kW}$ photovoltaic array, $\mathrm{CO}_{2}$ emissions drop by $30 \%$ to almost $100 \%$, depending on the season, relative to the same house without the RED WoLF system. The system has the potential to shift residential demand from peak power/peak times to low value electricity at a time of low demand.
\end{abstract}

Keywords: Energy Storage, Photovoltaic, Artificial Intelligence, Peak Shifting, Grid Integration

\section{Introduction}

Reducing $\mathrm{CO}_{2}$ emissions is a worldwide challenge and a major goal of European Union policy. This is reflected by many indicators, not least the high number of European research programs and funded projects aimed at Greenhouse gas reduction. Decarbonization of the built environment, one of the most $\mathrm{CO}_{2}$-intensive sectors of the global economy, is a key step towards a low-carbon Europe (European Climate Foundation, $(\mathrm{ECF})$ and is mentioned in the Europe 2020 strategy (Europe 2020 Strategy). Increasing the share of renewables in the production and consumption mix is another a major objective of the EU (European Union) policy, as evidenced by innovation funding programs (Cooperation Programme).

A major contribution to decarbonizing the built environment can be made by supplying dwellings with green energy. According to the UK (United Kingdom) Department for Business, Energy \& Industrial Strategy (BEIS), the domestic sector was responsible in 2017 for the consumption of 40.1 million tonnes of oil-equivalent. This amounts to $\sim 27 \%$ of total national consumption (Department for Business, energy \& Industrial Strategy, 2017), a

\footnotetext{
*Lead Contact, a.shukhobodskiy@leedsbeckett.ac.uk

** Corresponding author, colantuono@gmail.com
}

\begin{tabular}{|lr|}
\hline BEIS & Business, Energy and Industrial Strategy \\
EU & European Union \\
HSS & Hybrid Storage System \\
NWE & North West Europe \\
PV & Photovoltaic \\
RED WoLF & Rethink Electricity Distribution Without Load Following \\
SHs & Storage heaters \\
The Grid & Electric Grid \\
UK & The United Kingdom of Great Britain and Northern Ireland \\
\hline
\end{tabular}

List of Acronyms

percentage that increases if buildings other than dwellings are considered.

A number of strategies are currently considered at the industrial, academic and public authority level, to decarbonize energy supply to dwellings. This manuscript focuses on homes powered only by electricity. A model is proposed in which batteries and thermal storage are combined with behind-the-meter PV systems. Carbon reduction is achieved through maximization of local photovoltaic (PV) consumption and, more importantly, by means of storing electricity from the Power Grid (henceforth abbreviated to 'Grid') in times when the $\mathrm{CO}_{2}$ intensity of Grid electricity is low.

North West Europe (NWE), especially the British Isles and northern France, is particularly well suited for the 
electrification of domestic heating coupled to energy storage, due to it relatively mild winters resulting from the influence of the Atlantic ocean Peel, Finlayson and Mcmahon (2007); Colantuono, Wang. Hanna and Erdélyi (2014); Pozo-Vázquez, Tovar-Pescador, Gámiz-Fortis, EstebanParra and Castro-Díez (2004), and due to the projected increased penetration there of renewables, particular aeoliangenerated power, which is already leading to curtailment when high wind generation and low demand occur simultaneously. As a very recent publication points out (Le, Huang, Wilson, Shah and Hewitt, 2020), most of the existing literature focuses on reducing running costs or energy consumption rather than aiming to increase the uptake of green electricity, as is found in the present study approach to $\mathrm{CO}_{2}$ reduction.

Energy policy and energy landscape in NWE countries are also relevant factors in promoting homes powered solely by electricity. The UK's energy policy revolves around the energy trilemma (Royal Academy of Engineering); that is, the energy supply must be cheap, secure and clean. These three goals are not easily achieved simultaneously. However, electricity produced from green sources, and the removal of fossil fuels from houses, represent a significant step forward in this direction. In France, nuclear power plants generate $\sim 75 \%$ of the total national electricity. A significant fraction of these plants are ageing and not set to be replaced, and renewable penetration is increasing. This makes storage valuable: further $\mathrm{CO}_{2}$ reduction in homes can be achieved thanks to local PV and to storage, by means of reducing peak load and, in turn, integrating more renewables on the Grid. Ireland would greatly benefit from affordable electricity heating as most houses are still heated by oil, a high carbon fossil fuel $(68 \%$ of dwellings in Northern Ireland in 2010, up to $82 \%$ in rural areas. The Consumer Council https://www.energysavingtrust.org.uk/blog/northernireland-reducing-dependency-oil-fired-heating).

This manuscript introduces and experiments with a mathematical algorithm that proposes a novel strategy to store electricity in homes for all energy uses, from space and water heating to appliances and lighting. Modelled houses are endowed with a Hybrid Storage System (HSS) combining batteries, storage heaters ( $\mathrm{SHs}$ ) and hot water cylinders. SHs provide space heating on demand to individual rooms within $24 \mathrm{hrs}$. HSSs will store both the houses' PV output and low-carbon energy drawn from the Grid at times of low $\mathrm{CO}_{2}$ intensity. This strategy will remove the generation-demand temporal mismatch currently hindering the growth of renewables: when demand is low on sunny/windy days, output of solar/wind farms must be reduced. Every year, in some countries, up to almost $10 \%$ of available wind energy is curtailed (e.g. Northern Ireland in 2018, EirGrid-SONI) or achieves negative wholesale price. If no action is taken to facilitate the intake of intermittent/non dispatchable power, this figure is expected to grow as penetration of renewables on the Grid increases.
In order to identify the time interval during which electrical energy must be taken and stored, the model predicts the house energy requirements $\mathcal{E}$ for the next 24 hours, based on previous consumption patterns. PV generation for the next 24 hours is also predicted. Three separate predictions are made for space heating, hot water and appliances/lighting requirements. Such energy forecasts can be satisfied by taking electricity during the unknown time duration $T$ (that can be either simply connected, or the sum of several disjoint sub-intervals) at the maximum power intake $P$, which is predetermined for the house. Once the time duration $T=\mathcal{E} / P$ has been calculated, the subintervals of cumulative duration $T$ for electricity uptake are determined by the model. The prediction is updated every hour, and due to the lower cost of thermal mass with respect to battery capacity, the energy aimed at space and water heating is estimated and stored independently in the dwelling's thermal masses (SHs and water cylinder).

\subsection{The RED WoLF European project}

RED WoLF (Rethink Electricity Distribution Without Load Following) is an EU project funded by Interreg North West Europe. 100 houses, organized in 6 Pilot sites in EIRE, UK and France, are being equipped with battery storage, SHs, PV modules and a control network that can drive the storage reservoirs in the dwelling, according to the algorithmic rules and computations outlined in the previous paragraph, with the aim of reducing housing $\mathrm{CO}_{2}$ emission via a reduction of peak power intake. The present manuscript reports the results of a computer simulation based on these rules. Experimental data acquired in the Pilot sites will be discussed in future publications and compared with the simulations discussed in this manuscript.

\subsection{Main contribution}

Within the frame of Interreg NWE's call for proposals, RED WoLF responded to Priority 2 (Low Carbon) and Specific Objective 3, "To facilitate the uptake of low carbon technologies [...]" (Interreg NWE., 2019). The aim of the Project and of the present study is to combine two storage technologies that have not yet enjoyed full market acceptance (batteries for home storage; SHs). Smartly combining batteries with thermal reservoirs decreases the average cost of storage per kWh: advanced SHs with 30 kWh capacity cost $\sim 1000$ euros; a battery with equal capacity is ten times more expensive than this. Telaretti, Graditi, Ippolito and Zizzo 2016 concluded that the sole usage of batteries to shift peak demand could lead to the increase of overall expenditures, unless a time of use tariff with strong intra day price difference is used. The storage combination proposed here, while covering the main requirements of a house (appliances; space heating; domestic hot water) makes electricity intake adaptive to the Grid (by reducing peak load), to the environment (by cutting $\mathrm{CO}_{2}$ ) and increases self-consumption rather than just exporting $\mathrm{PV}$ power regardless of demand. SHs, previously 
deployed in the British Isles, Australia and France, came on the market more than half a century ago (with the Economy 7 tariff) to store energy from inflexible UK coal plants suffering from reduced night-demand due to deindustrialization. The present study (and the RED WoLF Project) is aimed at demonstrating that, in combination with batteries, these SHs can also become a viable solution also elsewhere, as nowadays it is crucial to store energy although for different purposes: to "make room" for the growing renewable generation on the Grid side, to increase behind-the-meter self-consumption and, ultimately, to reduce $\mathrm{CO}_{2}$ emissions. This combination has been selected as it also requires only electric wiring. Neither gas (already being phased out in some countries, e.g. the Netherlands, The Oxford Institute for Energy Studies. 2019) nor pipes nor plumbing are needed. $\mathrm{PV}$ is the only chosen source of domestic microgeneration since RED WoLF's pilot sites consist of social houses, and the public perception of technological risk is thus a prominent issue. The main innovations of this study (and of the RED WoLF project) are in the combination of thermal and battery storage, in the tracking of the $\mathrm{CO}_{2}$ signal to reduce $\mathrm{CO}_{2}$ emissions, and in the pilot houses self-adapting to Grid conditions without the need of external management.

The time series of PV output and Grid intake, and of the electricity flow inside the house (towards storage reservoirs and between battery and appliances) are simulated here. The objective is to schedule the electricity intake/storage that achieves the lowest average $\mathrm{CO}_{2}$ index over the next 24 hours, based on the predicted demand of the house over those same 24 hours. $\mathrm{CO}_{2}$ emissions are therefore reduced by acting on the "quality" of the consumed electrical energy.

Demand management is not considered: it is a layer that can be added on top of the RED WoLF system and it is already the subject of many studies. Likewise efficiency improvement of home appliances is not considered. The goal here is to assess (for now, via a simulation) how a combination of battery and thermal storage can reduce the $\mathrm{CO}_{2}$ emission associated with a given demand profile by "smartly" decoupling the scale of energy demand time series (due to space heating, domestic hot water and appliances) from electricity intake.

Individual elements of the RED WoLF system are well addressed in scientific literature. Sufyan, Rahim, Aman, Tan and Raihan (2019) present a review centred on the performance of different batterv technologies, while Arani, Gharehpetian and Abedi (2019) focus on battery control methods in microgrids. The review of Yan and Yang (2019) analyses latest achievements on thermal storage published between 2009 and 2017. They identify 5 articles focused on peak-load shifting and 20 on the wider topic of thermal storage in buildings. Felten and Weber (2018) concluded that the combination of a heat pump and a thermal storage may achieve financial for some specific technical characteristics and control models. Baeten, Rogiers and Helsen (2017) coupled a heat pump with a hot water tank dedicated to space heating. In order to perform thermodynamic work, the heat pump, despite being more energy efficient than SHs, requires power on demand. That leads to energy consumption during high $\mathrm{CO}_{2}$ or high price periods. A combination of water-based thermal reservoirs with heat pumps can reduce peak demand by controlling the usage of the pump. However, that requires a more complicated wet heating system. Moreover, SHs efficiently provide adjustable supply in different rooms within the dwelling, which may lead to further carbon reduction and financial savings.

The RED WoLF logic differs substantially from configurations involving heat pumps: the space heating is directly electrical and does not feature any circulating fluid, heat engines and moving parts. RED WoLF is geared toward future scenarios featuring abundant renewable but intermittent energy, where timing of electricity uptake is increasingly relevant with respect to the amount of energy used. Such scenarios are already peeking out: wind energy curtailment (Zhang, Lu, McElroy, Nielsen, Chen, Deng and Kang, 2016; Andoni, Robu, Frh and Flynn, 2017), energy's wholesale negative prices (Ederer, 2015) and the duck curve in California and elsewhere (Mills and Wiser, 2015; Hou, Zhang. Du. Miao. Peng and Kang, 2019).

Luthander, Widn, Nilsson and Palm (2015) discuss different strategies to improve PV self consumption. Widén (2014) addresses demand shifting via appliances management, while McKenna, McManus, Cooper and Thomson (2013) achieve a similar goal by means of introducing batteries in the system. In addition to a PV arrav, Kuboth, Heberle, König-Haagen and Brüggemann (2019) combine thermal storage with heat pumps and batteries to reduce the operation cost. Although their model shares the combination of batteries and thermal reservoirs with the present manuscript, it differs from it in many instances. Like in Baeten et al. (2017), space heating in Kuboth, Heberle, König-Haagen and Brüggemann (2019) is based on circulating hot water rather than SHs. Moreover, the present manuscript develops an original control strategy aimed at optimizing the time intervals of Grid's electricity intake: the RED WoLF algorithm is a function of the predicted Grid state, i.e Grid's $\mathrm{CO}_{2}$ intensity.

Wagh and Kulkarni (2018) review strategies to minimize $\mathrm{CO}_{2}$ emissions, a goal broadly similar to the objective of this manuscript. The papers analyzed therein are however focused with system planning and modelling rather than with driving/managing storage reservoirs in real time. Grosspietsch, Saenger and Girod (2019) analyze studies and practical implementations (i.e. pilot projects) focused on matching production and consumption, a goal which is present also in the present study: reducing Grid $\mathrm{CO}_{2}$ intake using storage offers an outlet to low-value electricity that is being curtailed increasingly often. Reda and Fatima (2019) discuss various ways of reducing electricity intake from the Grid, some of them include batteries and thermal storage combined; however, no SHs are used. Uddin, Romlie, Abdullah, Halim, Bakar and Kwang (2018) 
recommend the implementation of demand management strategies on top of energy storage. This resembles our vision: storage, which charges in an automated way, can either provide the basis for implementing a demand management strategy, or be used as it is by the least energyliterate dweller.

\section{Design of the RED WoLF System}

\subsection{Overview}

To reduce the intake of the $\mathrm{CO}_{2}$-intensive Grid electricity during peak hours, we introduce the hybrid storage system which is able to store energy in batteries and SHs for space heating, depending on the predicted need of the user. A PV array is present, and is allowed, together with the Grid, to charge batteries, SHs and to power appliances, with the only difference that the Grid is permitted to charge battery and $\mathrm{SHs}$ only when $\mathrm{CO}_{2}$ intensity drops below a certain threshold. In addition to that, the PV array is allowed to send excess power (in this context, power is labelled as 'excess' when all the electric load is satisfied, the battery is fully charged and the thermal storage reservoirs have reached the maximum capacity set for the day) to the Grid (see figure1).

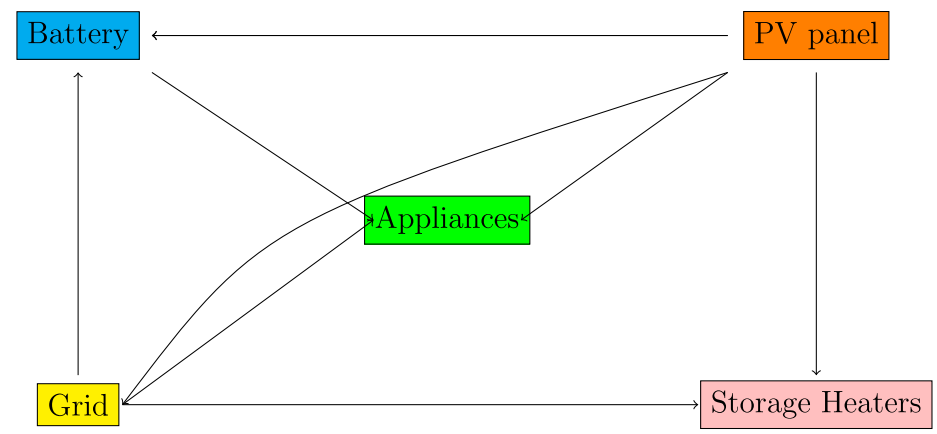

Figure 1: Schematic representation of the electricity distribution implemented in the RED WoLF project. Arrows represent the allowed flow of electricity within the system.

The ability to predict how and what kind of energy will be used will be ultimately defined by forecasts, for the next 24/48 hours, of PV output, $\mathrm{CO}_{2}$ Grid intensity, heat demand and appliances' demand. These forecasts will later be replaced by measured data to update predictions. A more detailed explanation of the procedure will be discussed in the following section.

Below, we briefly discuss the models used to estimate the generation of energy for the PV array. We employ weather forecast available on OpenWeather (2019) to estimate irradiance and convert it into PV. The Seo and Krarti (2011) model, which is emploving Kottek, Grieser, Beck, Rudolf and Rubel (2006) classification of different climate zones, is used to estimate global horizontal irradiance, where direct horizontal irradiance is estimated by DISC model Maxwell (1987). Finally with the aid of PV_LIB (National Technology and Engineering Solutions of Sandia, 2018) for Python the estimates of energy generation from the PV array are obtained. A detailed analysis and discussion will be the object of future publications, after data acquisition from pilot houses. The aim of this manuscript is to evaluate the proposed storage strategy, and the subsequent algorithm, based on the existing PV generation and the domestic consumption data.

\subsection{Simulation model}

In what follows we slightly alter the model originally outlined (figure 1) by adding a water cylinder into the system. This added component is used only to heat domestic hot water. This adds another degree of complexity and ultimately some of the households will not use a water cylinder but instead other possible sources of water heating (e.g. instant hot water). Thus, we propose an algorithm that can neglect this extra information.

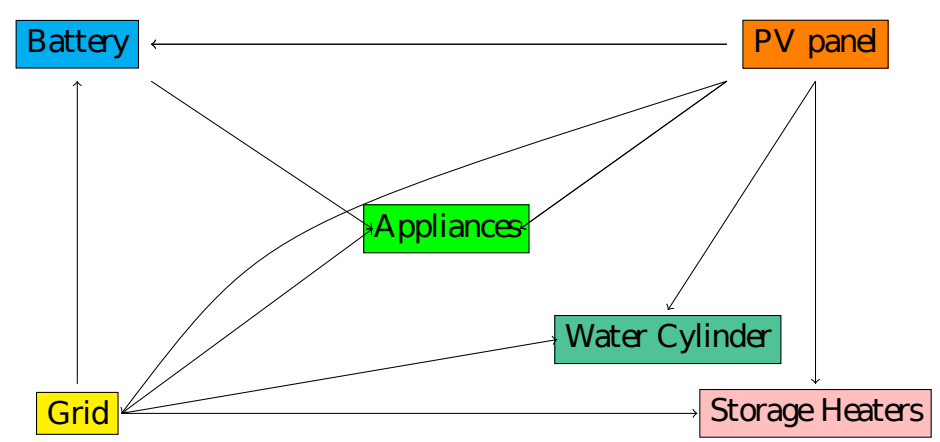

Figure 2: Schematic representation of the electricity distribution implemented in the RED WoLF simulation of performance. A water cylinder has been added with respect to figure 1

With the perspective of operating the system in pilot sites, we prove here the concept by means of numerical simulation. In what follows we will analyze the behavior of the algorithm on the existing time-series. We use the same domestic consumption profile and PV generation output as in Lichman, 2013: Colantuono, Kor, Pattinson and Gorse, 2018 obtained in Oxford (Oxford PV array (2016)), which is later scaled to $5 \mathrm{MWh}$ annual consumption, and we produce 3 different datasets of $\mathrm{PV}$ generation by taking $* 0.5, * 1$ and $* 2$ of the original $4 \mathrm{~kW}$ system. In the simulations reported here, this consumption profile plays the role of the forecast consumption time series; the "real" consumption is obtained by adding white noise. The same goes for PV output.

\section{The RED WoLF Algorithm}

In this section we briefly outline the system procedure. A list of variables is available in table 1

Some predefined parameters are not related to dwellers and are determined by the house's equipment: $H_{I M a x}$, $\tilde{H}_{I \operatorname{Max}}, C_{I \operatorname{Max}}, B_{I \operatorname{Max}}$ and $B_{\text {Max }}$. Other values may instead be chosen by the dweller or set up automatically in advance for the next $24 / 48$ hour period: $\tilde{H}_{\text {Setup }}$ and 


\begin{tabular}{|lr|}
\hline & Predefined parameters \\
$B_{I M a x}$ & Maximum rate of battery intake in $\mathrm{kW}$ \\
$B_{\text {Max }}$ & Maximum battery capacity in $\mathrm{kWh}$ \\
$C_{I M a x}$ & Maximum rate of cylinder intake in $\mathrm{kW}$ \\
$H_{I M a x}$ & Maximum rate of house intake from Grid in $\mathrm{kW}$ \\
$\tilde{H}_{I M a x}$ & Maximum rate of heat intake in $\mathrm{kW}$ \\
$B_{D}$ & Variables \\
$B_{\text {level }}$ & Battery demand in $\mathrm{kW}$ \\
$C_{D}$ & Battery level in $\mathrm{kWh}$ \\
$C_{\text {level }}$ & Cylinder demand in $\mathrm{kW}$ \\
$C_{S \text { Setup }}$ & Cylinder level in $\mathrm{kWh}$ \\
$\tilde{H}_{D}$ & The energy requited by user obtained in 24 hours in $\mathrm{kWh}$ \\
$\tilde{H}_{\text {level }}$ & Heat level in $\mathrm{kWh}$ \\
$\tilde{H}_{S e t u p}$ & Heand in $\mathrm{kW}$ \\
$P_{P 2 A}$ & The energy \\
$P_{P V}$ & needed for SHs to obtain in 24 in $\mathrm{kWh}$ \\
$T_{P V}$ & Predicted power to appliance in $\mathrm{kW}$ \\
$T_{P 2 B}$ & Predicted power from $\mathrm{PV}_{\text {in } \mathrm{kW}}$ \\
$T_{P F B}$ & Actual power from $\mathrm{PV}_{\text {in } \mathrm{kW}}$ \\
$T_{P 2 H}$ & Actual power to battery in $\mathrm{kW}$ \\
$T_{P 2 C}$ & Actual power from battery in $\mathrm{kW}$ \\
$T_{P F G}$ & Actual power to heat in $\mathrm{kW}$ \\
$T_{P 2 G}$ & Actual power to cylinder in $\mathrm{kW}$ \\
$T_{P 2 A}$ & Actual power from $\mathrm{Grid}_{2}$ in $\mathrm{kW}$ \\
$Q$ & Actual power to $\mathrm{Grid}$ in $\mathrm{kW}$ \\
$\delta$ & Actual power to appliance in $\mathrm{kW}$ \\
& $\mathrm{CO}_{2}$ intensity level prediction in $\mathrm{CO}_{2} / \mathrm{kWh}$ \\
& inten threshold in gCO $/ \mathrm{kWh}$ \\
\hline
\end{tabular}

Table 1: List of variables and predefined parameters

$C_{\text {Setup }}$. The other inputs required to simulate the system are the 48 hour PV generation forecast $P_{P V}$, the 48 hour $\mathrm{CO}_{2}$ intensity from the Grid forecast $Q$ and household consumption forecast $P_{P 2 A}$. All these input parameters and variables enable our system to operate in the next $24 / 48$ hours and are interpolated to generate numerical arrays with 1 minute step. In addition, we assume that the range of power intake for all devices can continuously vary from 0 to the maximum amount.

Now, we define heat demand, battery demand and cylinder demand as

$$
\begin{aligned}
\tilde{H}_{D} & =\tilde{H}_{\text {IMax }} H\left(\tilde{H}_{\text {Setup }}-\tilde{H}_{\text {level }}(\hat{t})\right), \\
B_{D} & =B_{\text {IMax }} H\left(B_{\text {Max }}-B_{\text {level }}(\hat{t})\right) \text { and } \\
C_{D} & =C_{\text {IMax }} H\left(C_{\text {Setup }}-C_{\text {level }}(\hat{t})\right)
\end{aligned}
$$

respectively, where $H(x)$ is the Heaviside step function and 1 in the domain of function represents the initial value of it. $C_{D}$ and $\tilde{H}_{D}$ are defined in similar fashion to $C_{D M a x}$ and $\tilde{H}_{D \text { Max }}$ with the only exception that $t>1$ for $C_{\text {level }}(t)$ and $\tilde{H}_{\text {level }}(t)$ in Equation (1). Then we introduce the integral balance of the system $\mathcal{I}$ and construct it as

$$
\begin{aligned}
\mathcal{I} & =\int_{\hat{t}}^{\mathcal{T}}\left(P_{P 2 A}(t)-P_{P V}(t)\right) / 60 d t \\
& +C_{\text {Setup }}-C_{\text {level }}(\hat{t})+\tilde{H}_{\text {Setup }}-\tilde{H}_{\text {level }}(\hat{t}),
\end{aligned}
$$

where $t$ is the time in minutes, $\hat{t}$ is the current time in minutes and $\mathcal{T}$ is time period for which our system run will be operational before the update of set up variables.
Equation (2) defines the difference between the total energy demand and the energy generated from the PV array at a given moment. If the value of $\mathcal{I}$ is non-positive, then, on average, the amount of generated energy exceeds the energy required for consumption. Otherwise, if $\mathcal{I}$ is positive, the average generated energy is lower than what is needed to satisfy consumption. This enables us to modify the time of Grid energy intake based on forecasts. In more details, it means that less energy is taken from the Grid for a higher forecast of PV generation and vice-versa.

We then introduce the rate of power intake.

$$
\omega=\int_{1}^{\mathcal{T}} P_{P 2 A}(t) d t / \mathcal{T}+\tilde{H}_{\text {IMax }}+B_{\text {IMax }}+C_{\text {IMax }}
$$

The allowed time of power intake $\mathcal{T}_{\text {int }}$ is defined as

$$
\begin{aligned}
& \mathcal{T}_{\text {int }} \\
& =\left[\max \left(\frac{60 \mathcal{I}}{\omega}, \frac{C_{\text {setup }}-C_{\text {level }}(1)}{C_{\text {IMax }}}, \frac{H_{\text {setup }}-H_{\text {level }}(1)}{H_{\text {IMax }}}\right)\right],
\end{aligned}
$$

where $\max (x, y, z)$ is the function which locates the maxima points $\forall x \wedge y \wedge z$ and $[x]$ is the nearest integer function of $x$. The second component of the max function on the right hand side of the equation is used to fix the minimum charging time needed for both SHs and the water cylinder, in case predicted energy generation and consumption differ from actual ones. Now, we rearrange the $Q$ array to obtain an array in monotonically increasing order $Q_{\text {sort }}$. This lets us to define the $\mathrm{CO}_{2}$ threshold for which energy is allowed to be taken from the Grid to charge the battery, SHs and water cylinder as

$$
\delta=Q_{\text {sort }}\left(\mathcal{T}_{\text {int }}\right) \text { for }>0 \text { or } \delta=0 \text { for } \mathcal{I} \leq 0 .
$$

We are now able to discuss the system procedure in more details. In general, whether the Grid will be used or not at any time $t$ will be defined by either $\delta>Q(t)$ or $\delta \leq Q(t)$. Below we present a more detailed explanation of how the system works by describing one step at a time the behavior of the algorithm. In what follows, unless stated otherwise, we consider all variables with exception of $\delta$ as a function of $t$.

First of all, in case $Q(t) \geq \delta$ and $T_{P 2 A}(t) \geq T_{P V}(t)$, if $\mathrm{PV}$ power does not cover demand, power is drawn from the battery to be used in appliances. If battery power is also insufficient, the system is forced to rely on the Grid to satisfy demand and nothing else will happen. Thus, we write

$$
\begin{aligned}
T_{P F G} & =\left(T_{P 2 A}-T_{P V}\right) \\
& \times H\left(T_{P 2 A} / 60-T_{P V} / 60-B_{\text {level }}\right), \\
T_{P F B} & =\left(T_{P 2 A}-T_{P V}\right) \\
& \times H\left(T_{P 2 A} / 60-T_{P V} / 60-B_{\text {level }}\right) .
\end{aligned}
$$

When $Q \geq \delta$ and $T_{P 2 A} \leq T_{P V}$ there is enough $\mathrm{PV}$ power to satisfy the electricity demand. As a result, we obtain 
the extra power $E=T_{P V}-T_{P 2 A}$. There are the four following options on how to proceed with this excess. In case $E<C_{d}$ then we transfer all of the extra power to the water cylinder to obtain

$$
T_{P 2 C}=E H\left(\tilde{H}_{\text {Setup }}-C_{\text {level }}\right) .
$$

On the other hand, if $E \geq C_{D}$ and $E<C_{D}+\tilde{H}_{D}$ then

$$
\begin{aligned}
& T_{P 2 C}=C_{D} \\
& T_{P 2 H}=\left(E-C_{D}\right) H\left(\tilde{H}_{\text {Setup }}-\tilde{H}_{\text {level }}\right) .
\end{aligned}
$$

That means that if we have enough power to cover the demand for the water cylinder and appliances, but not enough to charge SHs at maximum power rating, then we first charge the water cylinder and then SHs. The other option is $E \geq C_{D}+\tilde{H}_{D}$ and $E<C_{D}+\tilde{H}_{D}+B_{D}$. Therefore, the equations representing the performance of our algorithm will be

$$
\begin{aligned}
T_{P 2 C} & =C_{D} \\
T_{P 2 H} & =\tilde{H}_{D} \\
T_{P 2 B} & =\min \left(\left(E-C_{D}-\tilde{H}_{D}\right), B_{\text {IMax }}\right) \\
& \times H\left(B_{\text {Max }}-B_{\text {level }}\right),
\end{aligned}
$$

where $\min (x, y)$ is the function which locates the minima points $\forall x \wedge y$. As a result, in case the extra power $E$ suffices to charge both the water cylinder and SHs, but is still insufficient to charge the battery at maximum power rating, the latter will be charged by the excess power, below maximum battery intake. Finally, whenever $E>C_{D}+\tilde{H}_{D}+B_{D}, \mathrm{PV}$ power exceeds all the demand and thus we are able to export the excess to the Grid. Therefore, we write

$$
\begin{aligned}
& T_{P 2 C}=C_{D} \\
& T_{P 2 H}=\tilde{H}_{D} \\
& T_{P 2 B}=B_{D} \\
& T_{P 2 G}=E-\left(T_{P 2 C}+T_{P 2 H}+T_{P 2 B}\right) .
\end{aligned}
$$

We now consider the case when $Q<\delta$, so that the $\mathrm{CO}_{2}$ intensity level on the Grid is less than our calculated threshold. To be able to proceed further we introduce

$$
M_{H P V}=H_{I M a x}+T_{P V}
$$

the maximum power that can be directed into the house: it combines both maximum Grid power intake and the generated PV power. Since the level of $\mathrm{CO}_{2}$ is less then the threshold we are free to use cleaner energy from the Grid. Hence, the governing equations for the procedural run will be

$$
\begin{aligned}
T_{P 2 C} & =\min \left(C_{D},\left(M_{H P V}-T_{P 2 A}\right)\right. \\
& \left.\times\left(C_{\text {Setup }}-C_{\text {level }}\right)\right) \\
T_{P 2 H} & =\min \left(\tilde{H}_{D},\left(M_{H P V}-T_{P 2 A}-T_{P 2 C}\right)\right. \\
& \left.\times H\left(\tilde{H}_{\text {Setup }}-\tilde{H}_{\text {level }}\right)\right) \\
T_{P 2 B} & =\min \left(B_{D},\left(M_{H P V}-T_{P 2 A}-T_{P 2 C}-T_{P 2 H}\right)\right. \\
& \left.\times H\left(B_{\text {Max }}-B_{\text {level }}\right)\right) .
\end{aligned}
$$

Now, we might also have excess power if $T_{P V}>T_{P 2 B}+$ $T_{P 2 H}+T_{P 2 C}$, in which case we are able to send all the excess of power into the Grid.

The above is 1 minute step of the RED WoLF algorithm which will run for 24/48 hour period based on predictions for $\mathrm{CO}_{2}$ intensity level as well as predictions for PV output. In addition to that we update the $\mathrm{CO}_{2}$ intensity threshold only if the demand of SHs and the water cylinder is not satisfied due to deviation from the original prediction. The new threshold will be used by computing the new prediction values for $\mathrm{PV}$ generation as well as $\mathrm{CO}_{2}$ intensity level. This will improve the performance of the algorithm, in case the original predictions are different to the actual energy generation and consumption.

To summarize, we consider two options. The first one is when the threshold is below the current Grid $\mathrm{CO}_{2}$ intensity level. In which case the system first attempts to use the PV array to satisfy demand, with appliances having priority over the water cylinder. In turn, the water cylinder has the priority over SHs. SHs have the priority over the battery. Finally, the battery has the priority over the excess energy being exported to the Grid. However, if PV output is insufficient to satisfy appliances' demand, battery power is used; if the battery is empty, power is imported from the Grid. The opposite holds if the threshold is above current $\mathrm{CO}_{2}$ intensity level. In which case, we are free to use the Grid along with the PV array to satisfy the house demand. The hierarchy just outlined, with power directed first to appliances, then to the water cylinder, then to SHs and finally to the battery is summarized in the flowchart in figure A.10 (Appendix).

The order of charging might be explained from the point of a view of efficiency: a battery is less efficient than thermal storage (converting electricity into heat is $100 \%$ efficient) and therefore chosen the last. Water cylinders are prioritized over SHs because they leak less heat. Prioritizing the least leaky and most efficient reservoir will decrease losses in the RED WoLF pilot houses. Storage inefficiency and thermal leakage have not been taken into account in the simulation but will be carefully assessed during practical implementation. We also check if the SHs and water cylinder demand is satisfied in real time on an hourly basis. Results show that our algorithm is able to reduce the $\mathrm{CO}_{2}$ emission level during peak time while at the same time satisfying the demand of the dweller. Thus RED WoLF is a viable solution to be implemented in the household of a greener future.

\subsection{The comparison to other recent models}

Roberto, De Iulio, Di Somma, Graditi, Guidi and Noussan, 2019 (from now on model 1) analyze Power and heat co-generation (CHP) coupled to district heating. They concluded that thermal storage in district heating networks is convenient in presence of low flexibility of the supply side. Thermal storage systems are also useful in the case of large daily energy price fluctuations and to decrease the peak demand on the district heating network. 
The authors also deem heat storage beneficial as a balancing factor in view of the increased intermittency on the Grid resulting from the increasing share of renewables. These motifs are in line with those behind the RED WoLF concept, where storage is added as a buffer for intermittent renewables, but can in principle also compensate for scarce flexibility on the generation side.

Graditi, Ippolito, Telaretti and Zizzo, 2016 (from now on model 2) and Telaretti. Graditi. Ippolito and Zizzo, 2016 (model 3) concluded that batteries, when coupled to a time of use tariff, can be economically viable in, respectively, public buildings (model 2) and houses(model $3)$. Both models provide viable solutions to store the energy outside peak time and, like model 1, display similar goals to ours. The main difference is that RED WoLF combines the features of model 1 on one side and models 2-3 on the other, considering both thermal storage and chemical storage in combination. This presents different challenges from model 1 (where heat is co-generated outside the house, and batteries are not present) and models 2 and 3 (with no thermal storage). RED WoLF algorithm is required to split in advance the energy to be stored in one reservoir or the other. Firstly, because low grade heat cannot be converted back to electricity by any reasonable means; secondly, because using the battery to store energy for later use in heating would impose an additional inefficiency penalty and would require a battery capacity at least one order of magnitude larger, which nowadays is not financially sustainable.

Moreover, model 1 copes with district heating generated from gas, with the latest being planned to be phased out in Europe and indeed already being phased out in some countries (e.g. the Netherlands from 2050 on, The Oxford Institute for Energy Studies. 2019).

Other differences are more technical: instead of knowing in advance the price signal for the next day, our system is focusing solely on following the $\mathrm{CO}_{2}$ intensity and the $\mathrm{PV}$ generation forecast, with regular forecast updates throughout the day. As reminded above, the presence of thermal energy storage in our system forces us to make real time predictions as low grade heat cannot be efficiently reverted to electricity. Making predictions has a positive effect also on battery efficiency as storing too much in batteries creates needless efficiency losses. Finally, in contrast to models 1, 2 and 3, we focus on every individual dwelling separately, since each of them would have its own consumption prediction for SHs, water cylinders and appliances, which can vary drastically between two different dwellings depending on many factors.

\section{Behavior of the RED WoLF Algorithm using Existing Data as Input}

Here we are testing the behavior of the system on existing data. We simulate the system during four days, representative of the seasonal cycle. Recordings of consumption and PV generation during these davs are taken from Lichman, 2013 and Oxford PV array, 2016, respectively. This combination of datasets has already been used in Colantuono, Kor, Pattinson and Gorse, 2018. where the Lichman, 2013 consumption data (coming from the household in France) have been detrended and had their seasonal dependency removed, in order to eliminate any possible effect of electric heating if present. In short terms, only the pattern of electricity demand across the days has been retained. The PV generation data come instead from $\mathrm{Ox}$ ford, UK (Oxford PV array (2016)), while the time series of Grid $\mathrm{CO}_{2}$ intensity refer to Sheffield in 2018 (which represents the demand in a UK urbanised area). The four days are namely the winter solstice (21 of December), the spring equinox (20 of March), the summer solstice (20 of June) and the autumn equinox (23 of September). Then we normalize the available consumption time series to 5 MW output, a value close to the UK average in accordance to Enerdata (2019)(to put this figure into context, Romania features the lowest European yearly consumption, $\approx 1.5 \mathrm{MWh}$, while Sweden displays the highest, $\approx 10$ $\mathrm{MWh})$. We also assume that the actual PV output obtained from the Oxford data might be treated as the predicted one and we add variability to the system by considering four options $0,0.5 P_{P V}, P_{P V}=4 \sim k W$ and $2 P_{P V}(0$ $\mathrm{kW}, 2 \mathrm{~kW}, 4 \mathrm{~kW}$ and $8 \mathrm{~kW} \mathrm{PV}$ array respectively). This will allow us to stress test the system for various PV sizes. We also consider three different battery capacities namely 5,7 and $10 \mathrm{kWh}$.

We will simulate the pilot homes by adding white noise to the actual PV output as well as adding white noise to the actual normalized consumption. Thus we assume that $P_{P V}$ and $P_{P 2 A}$ is obtained directly from the Oxford data, whereas $T_{P V}=\left|P_{P V}+\gamma\right|$ and $T_{P 2 A}=$ $\left|P_{P V}+\kappa\right|$, where each iteration $\gamma$ and $\kappa$ are normally distributed random numbers obtained by Python procedure numpy.random.uniform $(-1,1,(\mathcal{T}, 1))$. The demand of the combined SHs during the winter solstice has been set to $80 \mathrm{kWh}$, during the spring equinox to $32 \mathrm{kWh}$, while during summer solstice and autumn equinox has been set to 0 . We also assume that the set up capacity of the water cylinder is $10.5 \mathrm{kWh}$ (The average charging time of the water cylinder is around 3 hours and 30 minutes with a 3 $\mathrm{kW}$ resisting element). Then, we assume that the maximum rate of house power intake from the Grid, maximum rate of power intake to $\mathrm{SHs}$, maximum rate of power intake to water cylinder and maximum amount of power intake to the battery are, respectively, $25 \mathrm{~kW}$ (as a benchmark, standard UK house has 30/32 A, ring circuits per floor and $52 \mathrm{~A}$ circuit for oven/cooker), $15 \mathrm{~kW}, 3 \mathrm{~kW}$ and 14 $\mathrm{kW}$. It is also assumed that power can take a continuous spectrum of values from 0 to the maximum amount; however, in some real devices, maximum values are the only possible allowed. Since the RED WoLF system has been designed to be used in various countries and households across North West Europe, the permitted energy intake from the Grid may vary significantly. We also set the ini- 
tial battery level to $4 \mathrm{kWh}$, water cylinder to $0.7 \mathrm{kWh}$ and initial SHs level at $6 \mathrm{kWh}$. Although the set up parameters are quite arbitrary, the results of our simulations suggest that totally empty storage reservoirs are quite rare. From the definition of the $\mathrm{CO}_{2}$ thresholds (equation (5)) follows that a lower initial level in storage reservoirs would lead to higher intake from the Grid. As a result, more $\mathrm{CO}_{2}$ would be emitted.

We are now able to analyze the results of the RED WoLF system simulation for the 24 hours.

Looking at table2, we conclude that the RED WoLF system reduces the $\mathrm{CO}_{2}$ emission, for all considered sizes of the PV array. The effect is more prominent during winter and spring, when there is high energy demand for heating. The absence of the battery increases $\mathrm{CO}_{2}$ emission. We can also see that having larger PV arrays significantly reduces $\mathrm{CO}_{2}$ emission level. Even in the scenario when all storage reservoirs are empty, the RED WoLF system reduces $\mathrm{CO}_{2}$ emissions by a significant amount. We should also note that table 2 excludes all further reduction of $\mathrm{CO}_{2}$ emission level due to the energy exported to the Grid. Although the energy is sent back to the Grid, the complexity of the Grid structure should be studied to investigate the contribution of export on the reduction of $\mathrm{CO}_{2}$ level for each individual property.

Figure 3 shows that the RED WoLF algorithm indeed avoids times with $\mathrm{CO}_{2}$ intensity level peaks. The PV generation forecast has a seasonal effect on the power taken from the Grid for both powering appliances and charging storage reservoirs. First of all, during the winter solstice, when the energy demand for heating is much bigger than at other times, the energy generated by $\mathrm{PV}$ has little effect on the $\mathrm{CO}_{2}$ threshold behavior. Around midday, a small separation in the $\mathrm{CO}_{2}$ threshold becomes nonetheless detectable between different PV sizes, due to the continuously sunny morning (4) which makes differences in PV output significant. The same holds also during the spring equinox. However, since the $\mathrm{CO}_{2}$ index on this particular spring equinox is much higher than on the previous winter solstice, and due to a cloudier sky (figure 4), the $\mathrm{CO}_{2}$ thresholds results are virtually insensitive to PV size.

On the days with no heat demand, threshold sensitivity to PV size is much higher due to the increased weight of PV output on total demand. During the summer solstice, due to the low energy demand, the $\mathrm{CO}_{2}$ threshold looks initially the same for all PV sizes, with exception to the case with no PV array. Later, the system "realizes" the demand from the water cylinder and updates the threshold computation for the smallest, non-zero PV array.

Note how the 0.5 PV curve "rebounds" at a higher level with respect to the zero $\mathrm{PV}$ array: in the $0 \mathrm{PV}$ case, the $\mathrm{CO}_{2}$ threshold is higher than at a previous time because a higher input on the Grid was needed earlier. This is confirmed by figure 8 , showing how in the summer solstice the charging of the water cylinders starts earlier for the $0 \mathrm{PV}$ system, which is enabled to draw electricity earlier thanks to the higher $\mathrm{CO}_{2}$ threshold.
A similar situation, although not identical, can be seen during the autumn equinox. However, due to the lower predicted PV generation, the 0.5 PV's threshold starts at the same level of the $0 \mathrm{PV}$ one. In this case, it is the system equipped with the $1 \mathrm{PV}$ array that needs a threshold adjustment in the early afternoon, as happened to $0.5 \mathrm{PV}$ in the summer case. The $2 \mathrm{PV}$ threshold remains instead unaffected, as the larger PV output does not require relaxing of the $\mathrm{CO}_{2}$ constraint for taking Grid electricity.

We can see that, in general, the lower the predicted PV output (see figure 4), the higher the $\mathrm{CO}_{2}$ threshold. This is due to $\mathrm{CO}_{2}$ intensity of $\mathrm{PV}$ power being zero.

The above situation can change depending on how much the actual, recorded demand and PV output time series, here emulated by adding white noise to the available time series (that play the role of predictions), differ from the predicted ones. The real system will need to systematically compare predicted time series with recorded ones. A high PV generation prediction means there is a higher likelihood of more energy being produced by the PV array. Consequently, the likelihood of using less energy from the Grid to satisfy demand is also higher. This will cause the algorithm to lower the threshold to avoid using the energy from the Grid.

Additional simulations, here not reported for brevity, show that if a non-adaptive $\mathrm{CO}_{2}$ threshold (i.e. based on a 24 hour prediction without hourly updates) is used, Grid uptake during peak times can be equally avoided. However, such a coarser threshold results in a higher chance of storage reservoirs running empty at the "wrong" time (in which case the Grid energy is taken at high $\mathrm{CO}_{2}$ times). To prevent this outcome, a less stringent threshold could be required. This however causes higher daily $\mathrm{CO}_{2}$ emissions, since a more relaxed threshold enables electricity uptake during suboptimal time intervals. The $\mathrm{CO}_{2}$ threshold used in RED WoLF algorithm is therefore adaptive, can be finetuned to recent emission and storage state of charge and is designed to avoid such drawbacks.

The "predicted" PV generation is presented in figure 4. As anticipated earlier, adding white noise creates a different time series, here used to emulate actual PV output. Although it is not an ideal construction from the physical point of view, white noise addition provides an extra time series, enabling us to run the simulation. It is also pointed out that storing energy is mathematically analogous to integrating power in time over the uptaking subintervals, which makes unrealistic white noise spikes irrelevant. White noise addition has also been used to obtain a proxy for the "real" appliances demand profile shown on figure 5 .

Figure 6] shows how the energy input to all SHs combined is only slightly affected by the PV generation profile. This is due to PV output being small (approximately by one order of magnitude) with respect to space heating demand, and also because PV is to some extent in phase with direct household's appliances demand, which has the priority on charging storage. Since $\mathrm{CO}_{2}$ intensity peaks 


\begin{tabular}{|c|c|c|c|c|}
\hline & Winter & Spring & Summer & Autumn \\
\hline \begin{tabular}{|l|} 
No RED WoLF \\
Scenario 1
\end{tabular} & 30698 & 22470 & 5221 & 6402 \\
\hline $\begin{array}{l}\text { No RED WoLF } \\
\text { Scenario } 2\end{array}$ & 32494 & 24234 & 5405 & 6476 \\
\hline \begin{tabular}{|l|} 
No RED WoLF \\
Scenario 3 \\
\end{tabular} & 24843 & 15836 & 2150 & 4363 \\
\hline \begin{tabular}{|l|} 
RED WoLF \\
No PV Array \\
7kWh Battery (all \\
storages empty) \\
\end{tabular} & 27697 & 18761 & 4606 & 5801 \\
\hline \begin{tabular}{|l|} 
RED WoLF \\
$4 \mathrm{~kW}$ PV Array \\
$7 \mathrm{kWh}$ Battery (all \\
storages empty) \\
\end{tabular} & 24115 & 14810 & 794 & 4072 \\
\hline $\begin{array}{l}\text { RED WoLF } \\
\text { No PV Array } \\
5 \text { kWh Battery } \\
\end{array}$ & 24989 & 16157 & 3940 & 5394 \\
\hline $\begin{array}{l}\text { RED WoLF } \\
2 \mathrm{~kW} \text { PV Array } \\
5 \mathrm{kWh} \text { Battery } \\
\end{array}$ & 23738 & 12766 & 2515 & 2773 \\
\hline $\begin{array}{l}\text { RED WoLF } \\
4 \text { kW PV Array } \\
5 \text { kWh Battery } \\
\end{array}$ & 21540 & 12301 & 27 & 1651 \\
\hline $\begin{array}{l}\text { RED WoLF } \\
8 \mathrm{~kW} \text { PV Array } \\
5 \mathrm{kWh} \text { Battery } \\
\end{array}$ & 21029 & 12170 & 0 & 316 \\
\hline $\begin{array}{l}\text { RED WoLF } \\
\text { No PV Array } \\
7 \text { kWh Battery } \\
\end{array}$ & 25340 & 16028 & 3869 & 5646 \\
\hline $\begin{array}{l}\text { RED WoLF } \\
2 \mathrm{~kW} \text { PV Array } \\
7 \text { kWh Battery } \\
\end{array}$ & 24090 & 12493 & 2896 & 2879 \\
\hline $\begin{array}{l}\text { RED WoLF } \\
4 \mathrm{~kW} \text { PV Array } \\
7 \text { kWh Battery } \\
\end{array}$ & 21540 & 12077 & 27 & 1910 \\
\hline $\begin{array}{l}\text { RED WoLF } \\
8 \text { kW PV Array } \\
7 \text { kWh Battery } \\
\end{array}$ & 21205 & 11968 & 0 & 316 \\
\hline \begin{tabular}{|l|} 
RED WoLF \\
No PV Array \\
10 kWh Battery \\
\end{tabular} & 25911 & 15765 & 3743 & 6203 \\
\hline $\begin{array}{l}\text { RED WoLF } \\
2 \text { kW PV Array } \\
10 \text { kWh Battery } \\
\end{array}$ & 24660 & 12609 & 4021 & 3395 \\
\hline $\begin{array}{l}\text { RED WoLF } \\
4 \text { kW PV Array } \\
10 \text { kWh Battery } \\
\end{array}$ & 21540 & 12609 & 27 & 2403 \\
\hline $\begin{array}{l}\text { RED WoLF } \\
8 \text { kW PV Array } \\
10 \text { kWh Battery } \\
\end{array}$ & 21204 & 12590 & 0 & 316 \\
\hline
\end{tabular}

Table 2: $\mathrm{CO}_{2}$ emission in $\mathrm{g}$ of $\mathrm{CO}_{2}$ in four selected days: winter solstice, spring equinox, summer solstice and autumn equinox. The daily heat demand (due to water cylinder and SHs) for those four days is specified in the main text. Scenario 1 represents the case with no RED WoLF and uniform heat demand throughout the day. Scenario 2 corresponds to the case without RED WoLF and the same total daily heat demand of Scenario 1, but being distributed across 8 hours grouped in two peak time intervals, $6 \mathrm{~h}-9 \mathrm{~h}$ and $17 \mathrm{~h}-22 \mathrm{~h}$, being constant therein with triple magnitude with respect to Scenario 1. Scenario 3 is like Scenario 1 with the addition of a $4 \mathrm{~kW}$ PV array. "All reservoirs empty" means that the energy in the water cylinder, SHs and battery is zero at $t=0$; the energy at $t=0$ in all other Scenarios is specified in the main text 

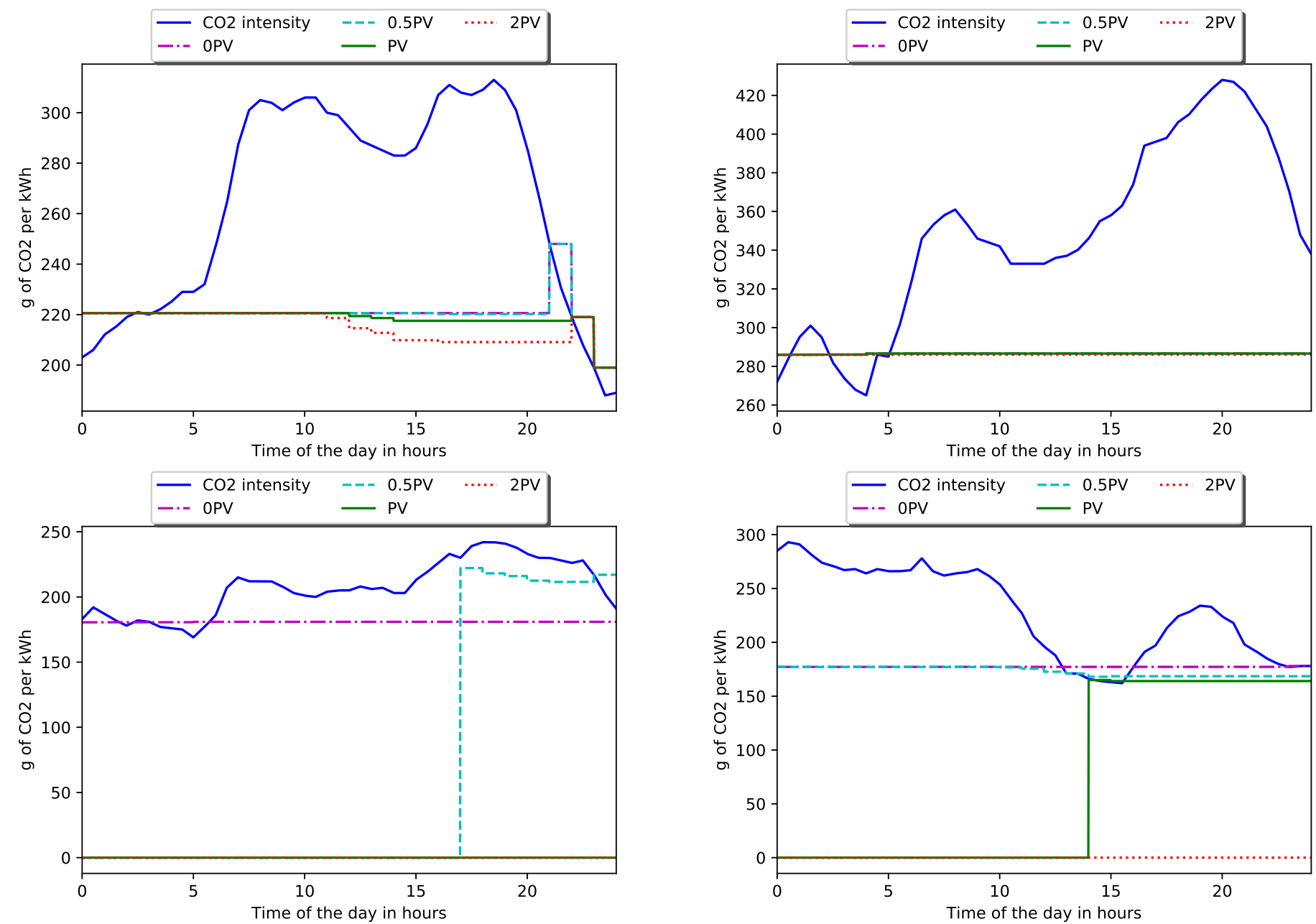

Figure 3: $\mathrm{CO}_{2}$ intensity level and threshold in $\mathrm{g}$ of $\mathrm{CO}_{2}$ per $\mathrm{kWh}$. The blue line represents the $\mathrm{CO}_{2}$ intensity level. The green line represents the $\mathrm{CO}_{2}$ threshold for the case of the "standard" $4 \mathrm{~kW} \mathrm{PV}$ array (1 PV in the next captions). The red, cyan, purple lines represent the $\mathrm{CO}_{2}$ threshold for the $2 \mathrm{PV}, 0.5 \mathrm{PV}$ and no-PV (0 PV in the next captions) cases, respectively. Top left, top right, bottom left, bottom right graphs refer to winter solstice, spring equinox, summer solstice and autumn equinox, respectively

usually occur during the day, the Grid is used to charge SHs during low $\mathrm{CO}_{2}$ intensity night-time periods. In addition to that, we conclude from our simulation that there is no deviation in the charge level of SHs if the battery capacity varies. This is due to battery capacity being an order of magnitude smaller than SHs capacity and designed to be charged the last.

In figure 7 the sensitivity of the state of charge of a $7 \mathrm{kWh}$ battery with respect to varying PV size is displayed in each of the four seasons. The analyses of a $5 \mathrm{kWh}$ and a $10 \mathrm{kWh}$ battery in the summer solstice are also displayed. The most evident result is that the battery charge level is virtually insensitive to PV size in winter. The RED WoLF algorithm is not required to top up the battery to full capacity, which is instead charged based on the power needs predicted by the algorithm. Nevertheless, there are some differences between actual energy stored in batteries. The first one is that higher capacity batteries preserve higher charge throughout 24 hours. In addition to that, higher
PV power results in faster charging of the battery or less energy usage from the battery, due to a higher fraction of power demand being directly satisfied without the intermediation of storage. We can also directly see the effect of the computed $\mathrm{CO}_{2}$ threshold on the battery level. Whenever there is the need of Grid energy and $\mathrm{CO}_{2}$ intensity level is higher than the $\mathrm{CO}_{2}$ threshold, then the power is drawn from the battery and the energy level of the latter drops down. On the other side whenever the $\mathrm{CO}_{2}$ intensity level is lower than the threshold, the battery is charged.

The water cylinder level presented in figure 8 varies as a function of PV size in winter, summer and autumn, whereas it is insensitive to PV size in the spring equinox. This result can be explained by the position of the $\mathrm{CO}_{2}$ threshold, which in first three cases allows the water cylinder to be charged directly from the Grid and the PV array, whereas in the spring equinox power is received only from the Grid, due to PV power being produced just after the water cylinder being charged. 

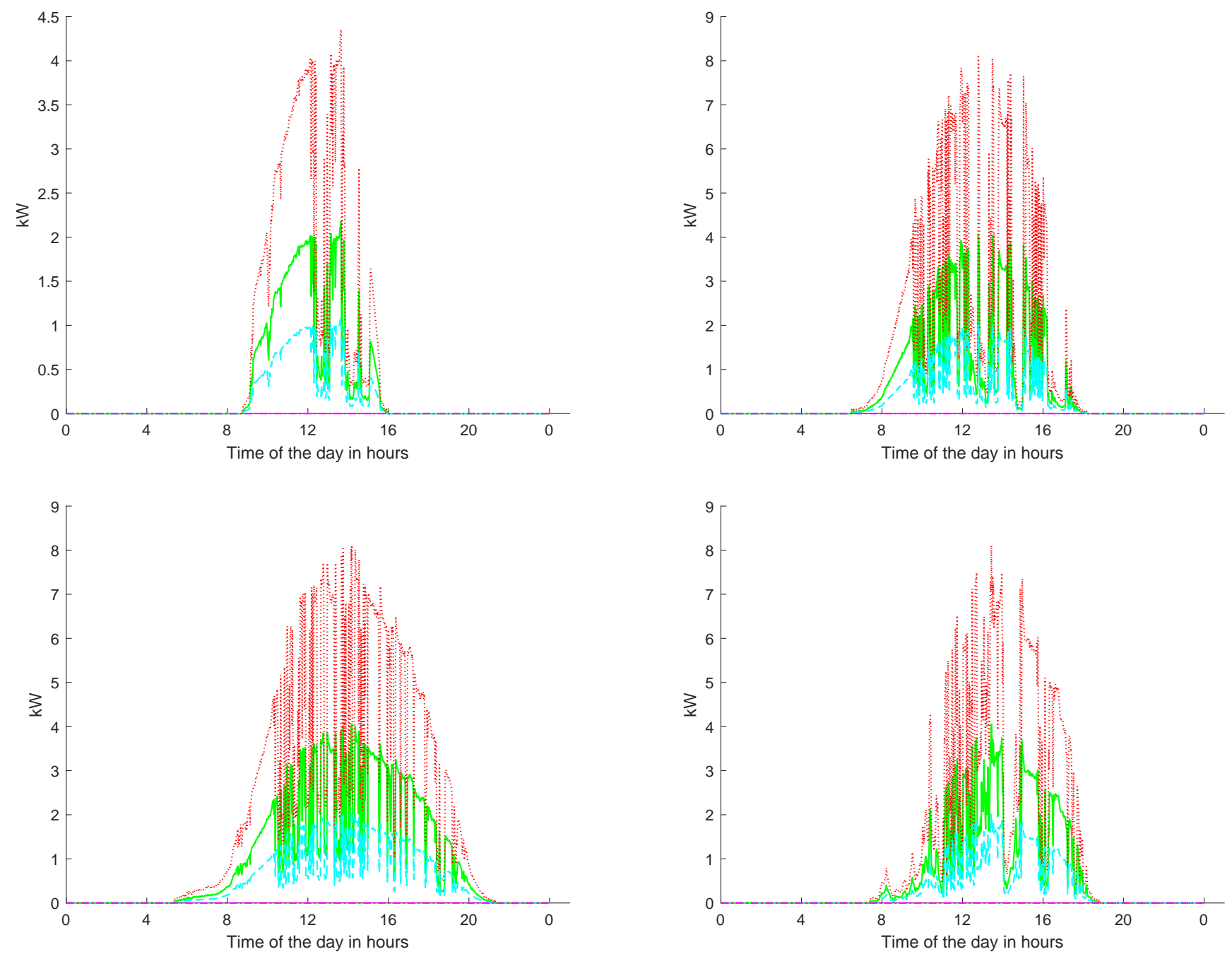

Figure 4: Predicted PV generation $\mathrm{kW}$. The green, red, cyan and purple lines represent the energy generated by a PV array of size 1 PV, $2 \mathrm{PV}, 0.5 \mathrm{PV}$ and $0 \mathrm{PV}$, respectively. Top left, top right, bottom left, bottom right graphs are obtained from the data taken in the winter solstice, in the spring equinox, in the summer solstice and in the autumn equinox respectively.

Finally we see from figure 9 that the excess of energy which is sent directly to the Grid is the most affected both by prediction of energy generated from the PV array as well as by the maximum capacity of the battery used in the household. The higher the rate of energy generated from PV the more energy will be sent back to the Grid. On the contrary the system with higher battery capacities will send less energy back to the Grid, since higher battery capacities are boosting the demand of low $\mathrm{CO}_{2}$ energy. Table 3 explicitly presents the energy sent back to the Grid in the simulated scenarios.

\section{Conclusion}

We have proposed the RED WoLF hybrid storage system to reduce $\mathrm{CO}_{2}$ emissions associated to energy usage in residential buildings. This is achieved thanks to a combination of batteries and thermal storage governed by an algorithm which encourages the intake of Grid electricity outside of peak times and increases PV self-consumption. Such an approach is unique of its kind: energy is stored in storage heaters and the water cylinder to satisfy demand of space heating and domestic hot water, respectively, while the rest of the anticipated and deferred electricity demand is covered by a battery. Electricity intake and storage are optimized with respect to the time series of predicted $\mathrm{CO}_{2}$ intensity of Grid electricity.

Battery output is not enabled to satisfy thermal demand, due both to the large amount of energy required to cover the heating load and to avoid unnecessary losses for converting to heat the chemical energy stored in the battery. The comparative high capacity and low price of thermal storage make the RED WoLF combination appealing to unleash the potential of domestic energy storage as the residential battery market is currently hampered by high prices. 

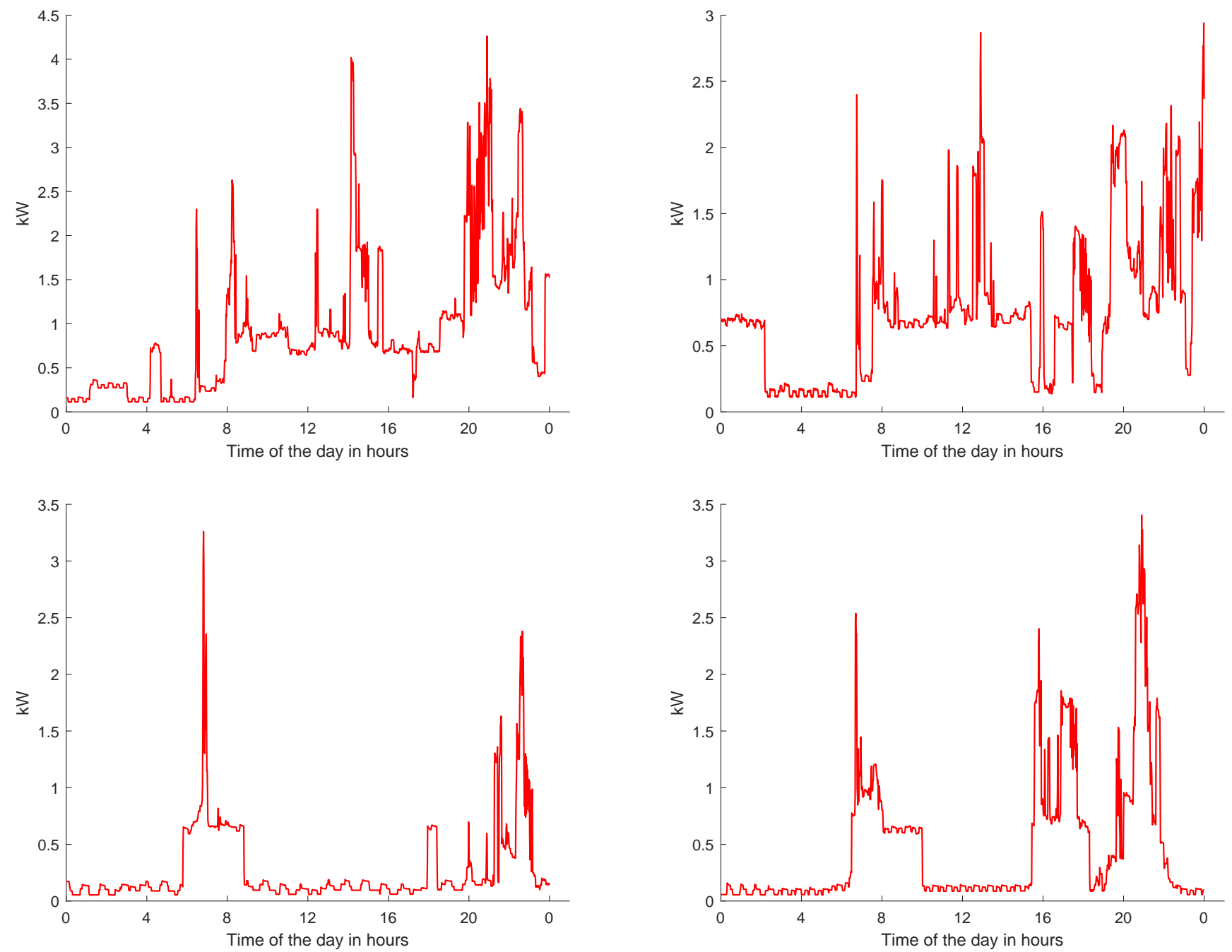

Figure 5: Predicted household demand in $\mathrm{kW}$ in the $1 \mathrm{PV}$ (i.e. $4 \mathrm{~kW}$ ) case. Top left, top right, bottom left, bottom right panel refers to winter solstice, spring equinox, summer solstice and autumn equinox, respectively.

The algorithm avoids the Grid's electricity intake during $\mathrm{CO}_{2}$ intensity peak time. The core task of the algorithm is the frequent recursive computation of the $\mathrm{CO}_{2}$ threshold, above which the intake of the Grid's power is forbidden. This threshold depends on the $\mathrm{CO}_{2}$ Grid profile, on the prediction of local domestic PV generation and on the predicted home energy consumption, based on environmental parameters and on household's historical data. The threshold is therefore a transient, ever changing benchmark which allows/forbids electricity intake based on the temporal locality of the consumption/PV output/ $\mathrm{CO}_{2}$ intensity predictions.

The RED WoLF model has been tested over four days in different seasons in a numerical experiment. Results are promising. The system shows the ability to meet demand while avoiding the usage of $\mathrm{CO}_{2}$-intensive Grid power. The usage of a battery with higher capacity successfully leads to lower usage of the "dirtier" Grid energy. It can be also concluded that the amount of predicted energy gener- ated by PV exerts a seasonal-dependent effect on the $\mathrm{CO}_{2}$ threshold, due to the lower/higher weight of PV output on the mix of consumed electricity when space heating is off/on.

The main achievement of the system is the significant reduction of domestic $\mathrm{CO}_{2}$ emission even when a $\mathrm{PV}$ array is not present. This key result testifies RED WoLF's induced carbon reduction thanks to the thermal/chemical reservoirs combined with algorithmic and predictive support. This manuscript shows how a house can suppress peak demand and reduce $\mathrm{CO}_{2}$ emission independently from demand management (which can be eventually superposed to the system) and adaptively, without the need of any centralized control on the supply side.

In the standard configuration, with a $4 \mathrm{~kW}$ PV array and a $7 \mathrm{kWh}$ battery installed, the simulated $\mathrm{CO}_{2}$ emission decreases by a fraction ranging from $30 \%$ in wintertime to almost $100 \%$ during summer compared to a house without the system. Doubling the battery size from $5 \mathrm{kWh}$ 

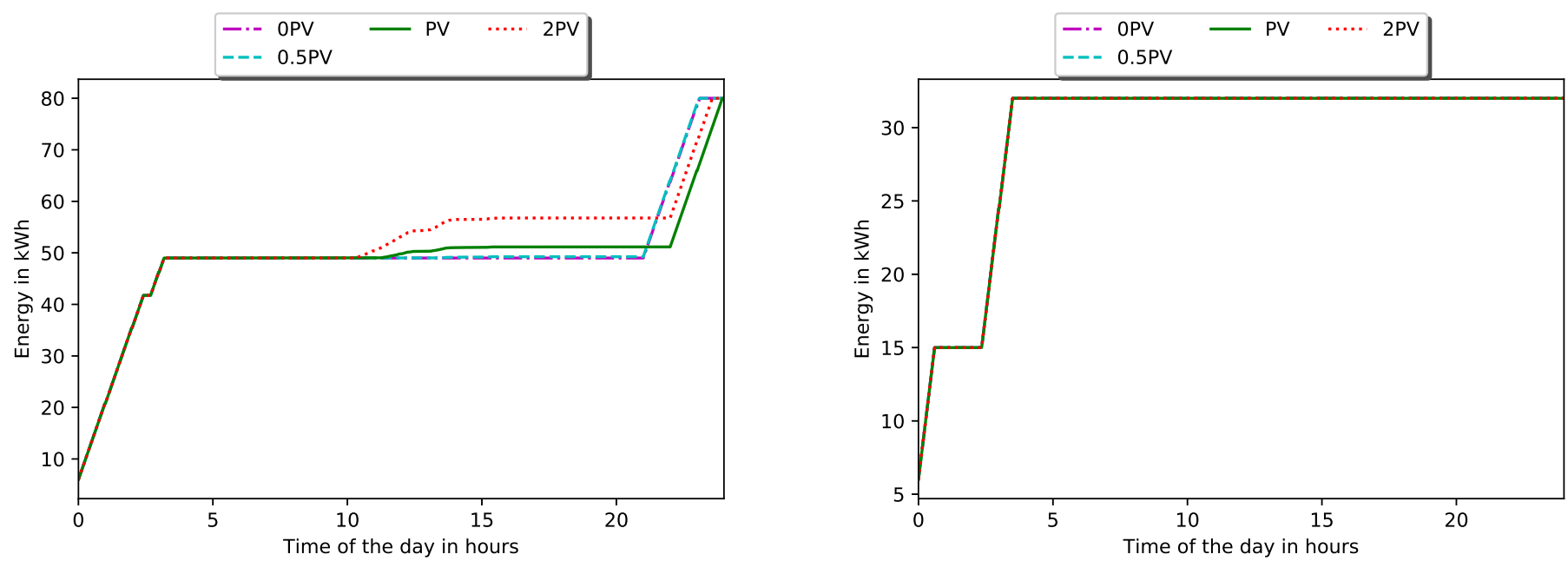

Figure 6: SHs energy input in $\mathrm{kWh}$ for battery maximum capacity of $7 \mathrm{kWh}$. The green, red, cyan and purple lines represent the scenario with PV array of size $1 \mathrm{PV}, 2 \mathrm{PV}, 0.5 \mathrm{PV}$ and $0 \mathrm{PV}$, respectively. The left (right) panel refers to the winter solstice (spring equinox).

\begin{tabular}{|l|l|l|l|l}
\hline & WINTER & SPRING & SUMMER & AUTUMN \\
\hline $\begin{array}{l}\text { RED WoLF } \\
\text { 0.5 PV Array } \\
\text { Battery } 5 \mathrm{kWh}\end{array}$ & 0 & 0 & 0 & 0 \\
\hline $\begin{array}{l}\text { RED WoLF } \\
1 \text { PV Array } \\
\text { Battery } 5 \mathrm{kWh}\end{array}$ & 0 & 4.9 & 2.3 & 0.9 \\
\hline $\begin{array}{l}\text { RED WoLF } \\
\text { 2 PV Array } \\
\text { Battery } 5 \mathrm{kWh}\end{array}$ & 0 & 18.6 & 25.6 & 7.6 \\
\hline $\begin{array}{l}\text { RED WoLF } \\
0.5 \text { PV Array } \\
\text { Battery } 7 \mathrm{kWh}\end{array}$ & 0 & 0 & 0 & 0 \\
\hline $\begin{array}{l}\text { RED WoLF } \\
1 \text { PV Array } \\
\text { Battery } 7 \mathrm{kWh}\end{array}$ & 0 & 4.9 & 0.5 & 0.9 \\
\hline $\begin{array}{l}\text { REDWoLF } \\
\text { 2 PV Array } \\
\text { Battery } 7 \mathrm{kWh}\end{array}$ & 0 & 18.6 & 23.8 & 5.5 \\
\hline $\begin{array}{l}\text { RED WoLF } \\
\text { 0.5 PV Array } \\
\text { Battery 10 kWh }\end{array}$ & 0 & 0 & 0 & 0 \\
\hline $\begin{array}{l}\text { RED WoLF } \\
1 \text { PV Array } \\
\text { Battery 10 kWh }\end{array}$ & 0 & 18.6 & 20.7 & 2.6 \\
\hline $\begin{array}{l}\text { RED WoLF } \\
\text { 2 PV Array } \\
\text { Battery 10 kWh }\end{array}$ & 0 & 4.9 & 0 & 0.9 \\
\hline
\end{tabular}

Table 3: The excess of power directed back to the Grid in $\mathrm{kWh}$

to $10 \mathrm{kWh}$ causes the RED WoLF system, endowed with a $4 \mathrm{~kW} \mathrm{PV}$ array, to augment $\mathrm{CO}_{2}$ reduction from $31 \%$ to $37 \%$ in winter and from $94 \%$ to $100 \%$ in summer. On the other hand, with a battery size fixed at $7 \mathrm{kWh}$ and a PV array assuming the values of 2,4 and $8 \mathrm{~kW}, \mathrm{CO}_{2}$ drops by $22 \%-30 \%-31 \%$ in winter and by $65 \%-99 \%-100 \%$ in summer, suggesting that the environmental benefit of increasing PV size is small above $4 \mathrm{~kW}$. RED WoLF can potentially also reduce the Grid's $\mathrm{CO}_{2}$ index by exporting excess PV output. This effect should be investigated further depending on national regulations and on the local Grid's state at the time of export.

Although carbon reduction is the main goal of the RED WoLF algorithm, replacing a $\mathrm{CO}_{2}$ signal with a price signal in the simulations will shed light on the performance of the system for reducing utility bills, and will provide a financial benchmark to establish its economic viability in comparison to potentially competing technologies and solutions. Comparing the emissions resultant from following a $\mathrm{CO}_{2}$ signal versus following a price signal will also be possible.

The RED WoLF algorithm will be tested in pilot sites once the construction/refurbishment of the houses therein will be complete. This will generate a unique dataset to be explored to understand the environmental and financial effect of combining thermal and battery storage in dwellings.

\section{Author Contribution}

All authors contributed equally

\section{Declaration of Interest}

The authors declare no competing interests

\section{Acknowledgemnt}

This work has been supported by the European Regional Development Fund, project RED WoLF, project number NWE847.

The authors also thank Geert Verhoeven for useful discussions. Geert is a Senior electrical engineer at VOLTA, the research and training centre for Belgian electricians.

\section{Appendix A. Appendix}

\section{References}

Andoni, M., Robu, V., Frh, W.G., Flynn, D., 2017. Game-theoretic modeling of curtailment rules and network investments with distributed generation. Applied Energy 201, $174-187$. 
Arani, A.K., Gharehpetian, G.B., Abedi, M., 2019. Review on energy storage systems control methods in microgrids. International Journal of Electrical Power \& Energy Systems 107, 745 - 757. doi https://doi.org/10.1016/j.ijepes.2018.12.040.

Baeten, B., Rogiers, F., Helsen, L., 2017. Reduction of heat pump induced peak electricity use and required generation capacity through thermal energy storage and demand response. Applied Energy 195, 184 - 195. doi https://doi.org/10.1016/j.apenergy.2017.03.055

Colantuono, G., Kor, A.L., Pattinson, C., Gorse, C., 2018. PV with multiple storage as function of geolocation. Solar Energy 165, 217-232. doi 10.1016/j.solener.2018.03.020

Colantuono, G., Wang, Y., Hanna, E., Erdélyi, R., 2014. Signature of the north atlantic oscillation on british solar radiation availability and pv potential: The winter zonal seesaw. Solar Energy 107, 210-219.

Cooperation Programme, 2014. Cooperation Programme Interreg North-West Europe $2014 \quad$ - 2020. https://www.nweurope.eu/media/1520/

interreg-nwe-cooperation-programme.zip

Department for Business, energy \& Industrial Strategy, 2017. Energy Flow Chart 2017. https://www.gov.uk/government/statistics/ energy-flow-chart-2017

Ederer, N., 2015. The market value and impact of offshore wind on the electricity spot market: Evidence from germany. Applied Energy 154, $805-814$.

EirGrid-SONI, 2019. Annual Renewable Energy Constraint and Curtailment Report 2018 http://www .eirgridgroup.com/site-files/library/EirGrid/ Annual-Renewable-Constraint-and-Curtailment-Report-2018 $-\mathrm{V} 1.0 . \mathrm{pdf}$

Enerdata, 2019. Enerdata intelligence + Consulting. https://www.odyssee-mure.eu/publications/efficiency-by-sector /households/electricity-consumption-dwelling.html

Europe 2020 Strategy, 2010. A European strategy for smart, sustainable and inclusive growth. https://ec.europa.eu/eu2020/

European Climate Foundation (ECF), 2010. A practical guide to a prosperous, low-carbon Europe. https://www.roadmap2050.eu/

Felten, B., Weber, C., 2018. The value(s) of flexible heat pumps assessment of technical and economic conditions. Applied Energy 228, $1292-1319$. doi https://doi.org/10.1016/j.apenergy.2018.06.031.

Graditi, G., Ippolito, M.G., Telaretti, E., Zizzo, G., 2016. Technical and economical assessment of distributed electrochemical storages for load shifting applications: An italian case study. Renewable and Sustainable Energy Reviews 57, 515-523. URL: WwW.scopus.com cited By :65.

Grosspietsch, D., Saenger, M., Girod, B., 2019. Matching decentralized energy production and local consumption: A review of renewable energy systems with conversion and storage technologies. WIREs Energy and Environment 8, e336. doi 10.1002/wene.336 arXiv:https://onlinelibrary.wiley.com/doi/pdf/10.1002/wene.33

Hou, Q., Zhang, N., Du, E., Miao, M., Peng, F., Kang, C., 2019. Probabilistic duck curve in high pv penetration power system: Concept, modeling, and empirical analysis in china. Applied Energy 242, $205-215$

Interreg NWE., 2019. Programme Manual v.10.

Kottek, M., Grieser, J., Beck, C., Rudolf, B., Rubel, F., 2006. World Map of the Köppen-Geiger climate classification updated. Meteorologische Zeitschrift 15, 259-263. doi 10.1127/0941-2948/2006/0130 https://www . ingentaconnect. com/content/schweiz/mz/2006 url/00000015/00000003/art00001.

Kuboth, S., Heberle, F., König-Haagen, A., Brüggemann, D., 2019. Economic model predictive control of combined thermal and electric residential building energy systems. Applied Energy 240, 372 - 385. doi https://doi.org/10.1016/j . apenergy.2019.01.097

Le, K.X., Huang, M.J., Wilson, C., Shah, N.N., Hewitt, N.J., 2020. Tariff-based load shifting for domestic cascade heat pump with enhanced system energy efficiency and reduced wind power curtailment. Applied Energy 257, 113976.
Lichman, M. 2013. UCI machine learning repository. http://archive.ics.uci.edu/ml

Luthander, R., Widn, J., Nilsson, D., Palm, J., 2015. Photovoltaic self-consumption in buildings: A review. Applied Energy 142, 80 - 94. doi https://doi.org/10.1016/j.apenergy.2014.12.028

Maxwell, E.L., 1987. A quasi-physical model for converting hourly global horizontal to direct normal insolation. Technical Report.

McKenna, E., McManus, M., Cooper, S., Thomson, M., 2013. Economic and environmental impact of lead-acid batteries in gridconnected domestic pv systems. Applied Energy 104, 239 - 249. doi https://doi.org/10.1016/j . apenergy .2012.11.016

Mills, A.D., Wiser, R.H., 2015. Strategies to mitigate declines in the economic value of wind and solar at high penetration in california. Applied Energy 147, 269 - 278.

National Technology and Engineering Solutions of Sandia, 2018. PV_LIB toolbox for Matlab. https://pvpmc.sandia.gov/applications/pv_lib-toolbox/

OpenWeather, 2019. OpenWeather. https://openweathermap.org/

Oxford PV array, 2016. https://shkspr.mobi/blog/2014/12/a-yearof-solar-panels-open-data/.

Peel, M.C., Finlayson, B.L., Mcmahon, T.A., 2007. Updated world map of the Köppen-Geiger climate classification. Hydrology and Earth System Sciences Discussions 4, 439-473.

Pozo-Vázquez, D., Tovar-Pescador, J., Gámiz-Fortis, S., EstebanParra, M., Castro-Díez, Y., 2004. Nao and solar radiation variability in the european north atlantic region. Geophysical Research Letters 31 .

Reda, F., Fatima, Z., 2019. Northern european nearly zero energy building concepts for apartment buildings using integrated solar technologies and dynamic occupancy profile: Focus on finland and other northern european countries. Applied Energy 237, 598 - 617 . doi https://doi.org/10.1016/j.apenergy.2019.01.029

Roberto, R., De Iulio, R., Di Somma, M., Graditi, G., Guidi, G. Noussan, M., 2019. A multi-objective optimization analysis to assess the potential economic and environmental benefits of distributed storage in district heating networks: a case study. International Journal of Sustainable Energy Planning and Management 20. doi \{https://doi.org/10.5278/ijsepm.2019.20.2\}.

Royal Academy of Engineering, 2015. A critical time for UK energy policy. What must be done now to deliver the UK future energy system. https://www.raeng.org.uk/publications/reports /a-critical-time-for-uk-energy-policy

Seo, D., Krarti, M., 2011. Hourly Solar Radiation Model Suitable for Worldwide Typical Weather File Generation. JOURNAL OF SOLAR ENERGY ENGINEERING-TRANSACTIONS OF THE ASME 133. doi 10.1115/1.4003883

Sufyan, M., Rahim, N.A., Aman, M.M., Tan, C.K., Raihan, S.R.S. 2019. Sizing and applications of battery energy storage technologies in smart grid system: A review. Journal of Renewable and Sustainable Energy 11, 014105.

Telaretti, E., Graditi, G., Ippolito, M.G., Zizzo, G., 2016. Economic 36. feasibility of stationary electrochemical storages for electric bill management applications: The italian scenario. Energy Policy 94, 126-137. Cited By :34.

The Consumer Council, 2011. mestic Heating Oil and Fuel Poverty. http://www.niassembly.gov.uk/globalassets/documents /social-dev/fuel-poverty/heatingoil_fuel-poverty.pdf

The Oxford Institute for Energy Studies., 2019. The great Dutch gas transition.

Uddin, M., Romlie, M.F., Abdullah, M.F., Halim, S.A., Bakar, A.H.A., Kwang, T.C., 2018. A review on peak load shaving strategies. Renewable and Sustainable Energy Reviews 82, 3323 - 3332. doi https://doi.org/10.1016/j.rser.2017.10.056

Wagh, M., Kulkarni, V., 2018. Modeling and optimization of integration of renewable energy resources (rer) for minimum energy cost, minimum co2 emissions and sustainable development, in recent years: A review. Materials Today: Proceedings 5, 11 21. doi https://doi.org/10.1016/j.matpr.2017.11.047 international Conference on Processing of Materials, Minerals and Energy (July 29th - 30th) 2016, Ongole, Andhra Pradesh, India. 
Widén, J., 2014. Improved photovoltaic selfconsumption with appliance scheduling in 200 singlefamily buildings. Applied Energy 126, 199 - 212. doi https://doi.org/10.1016/j.apenergy.2014.04.008.

Yan, J., Yang, X., $2019 . \quad$ Thermal energy storage. Applied Energy 240, A1 - A6. doi https://doi.org/10.1016/j.apenergy.2018.03.001

Zhang, N., Lu, X., McElroy, M.B., Nielsen, C.P., Chen, X., Deng, Y., Kang, C., 2016. Reducing curtailment of wind electricity in china by employing electric boilers for heat and pumped hydro for energy storage. Applied Energy 184, 987 - 994. 

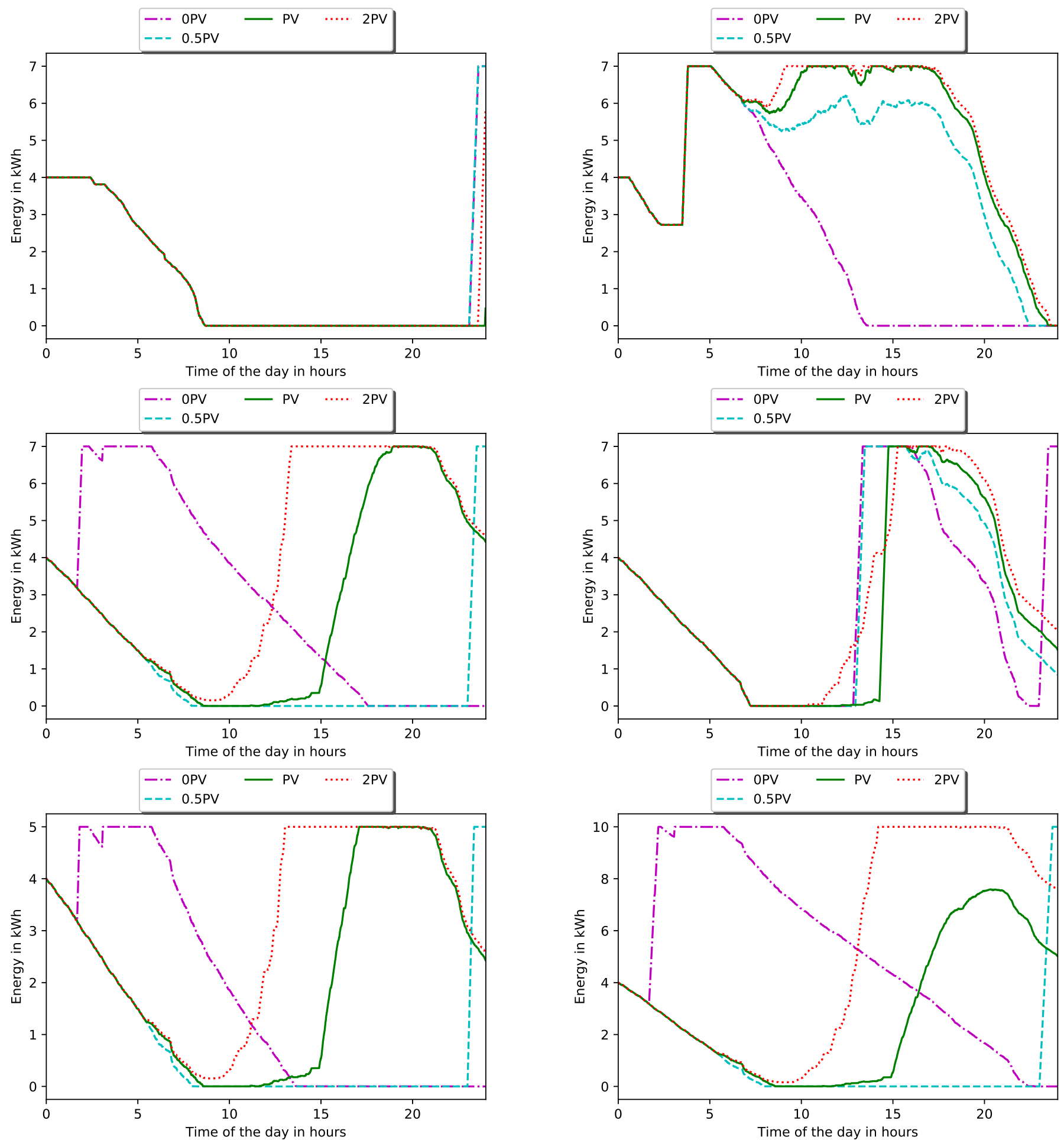

Figure 7: The top and middle panels display the level of charge of a battery with capacity of $7 \mathrm{kWh}$ in combination with PV arrays of varying size. The green, red, cyan and purple line refers to a PV size of $1 \mathrm{PV}, 2 \mathrm{PV}, 0.5 \mathrm{PV}$ and 0 PV, respectively. Top left, top right, middle left, middle right panels refer to winter solstice, spring equinox, summer solstice and autumn equinox, respectively. The bottom panels refer to the summer solstice, with left and right panel corresponding to maximum battery capacities of 5 and $10 \mathrm{kWh}$, respectively. 

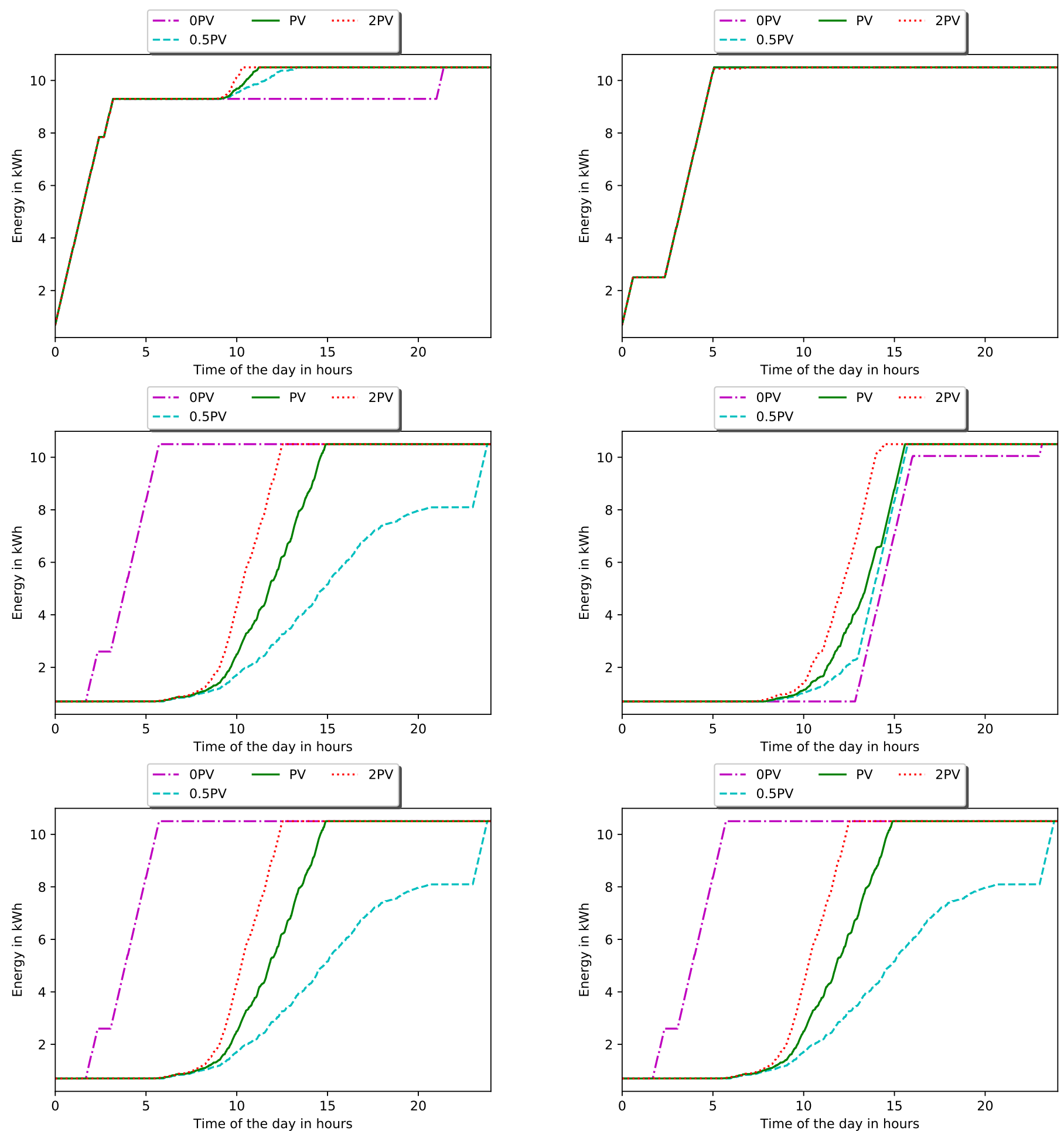

Figure 8: The top and middle panels display the water cylinder level in $\mathrm{kWh}$ for battery maximum capacity of $7 \mathrm{kWh}$. The green, red, cyan and purple lines represent the energy generated by a PV array of size 1 PV, 2 PV, 0.5 PV and 0 PV (i.e. no PV), respectively. Top left, top right, middle left, middle right panels refer to winter solstice, spring equinox, summer solstice and autumn equinox, respectively. Bottom panels bot refer to summer solstice, with left (right) panel corresponding to a maximum battery capacity of $5 \mathrm{kWh}(10 \mathrm{kWh})$. 

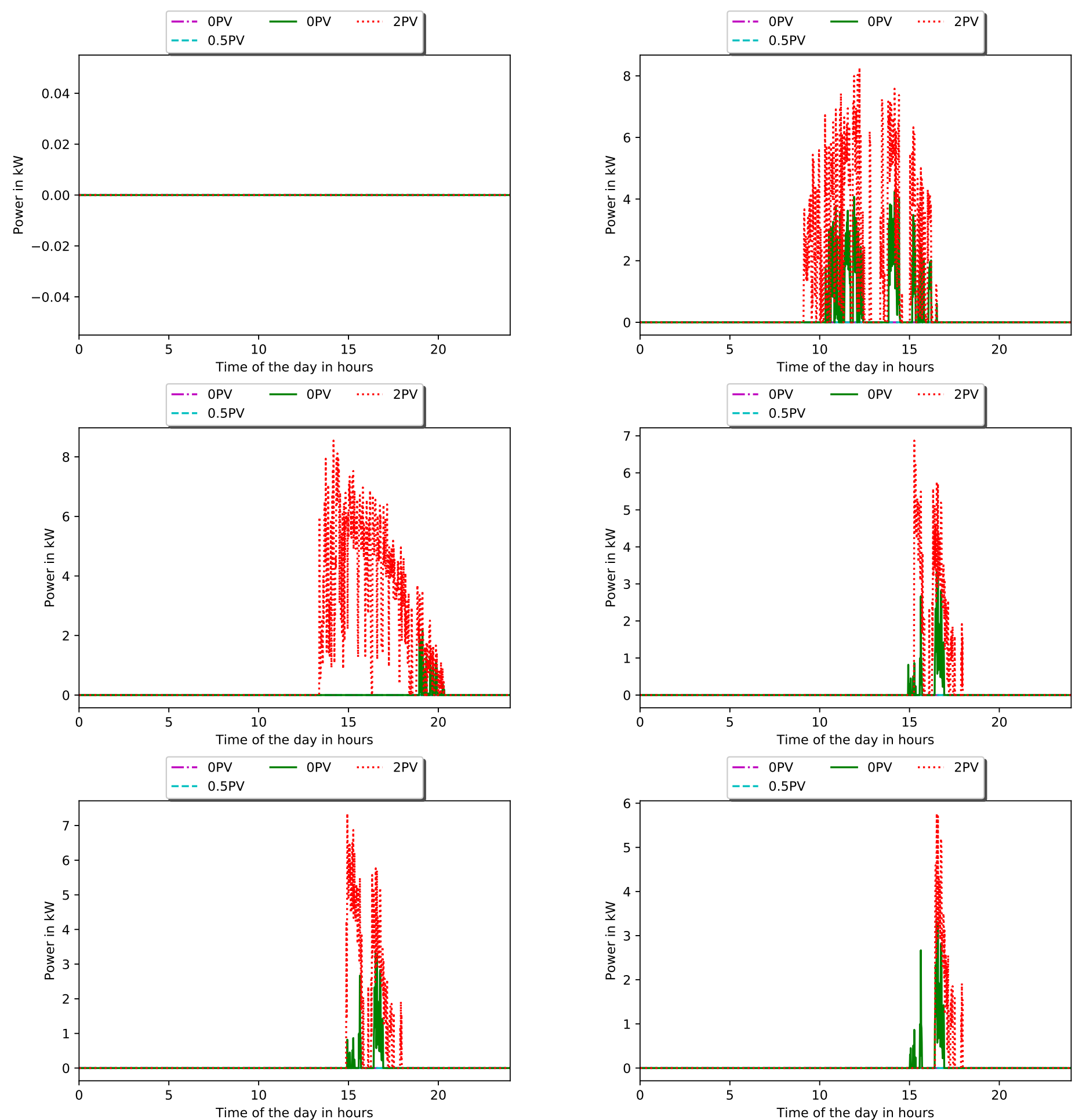

Figure 9: Excess power exported to the Grid in $\mathrm{kW}$. The top and middle panels correspond to the maximum battery capacity of $7 \mathrm{~kW}$. The green, red, cyan and purple lines represent the energy generated by a PV array of size 1 PV, 2 PV, 0.5 PV and 0 PV, respectively. Top left, top right, middle left, middle right panels refer to winter solstice, spring equinox, summer solstice and autumn equinox, respectively. Both bottom panels relate to the autumn equinox, with left (right) panel corresponding to maximum battery capacities of $5 \mathrm{kWh}$ (10 kWh). 


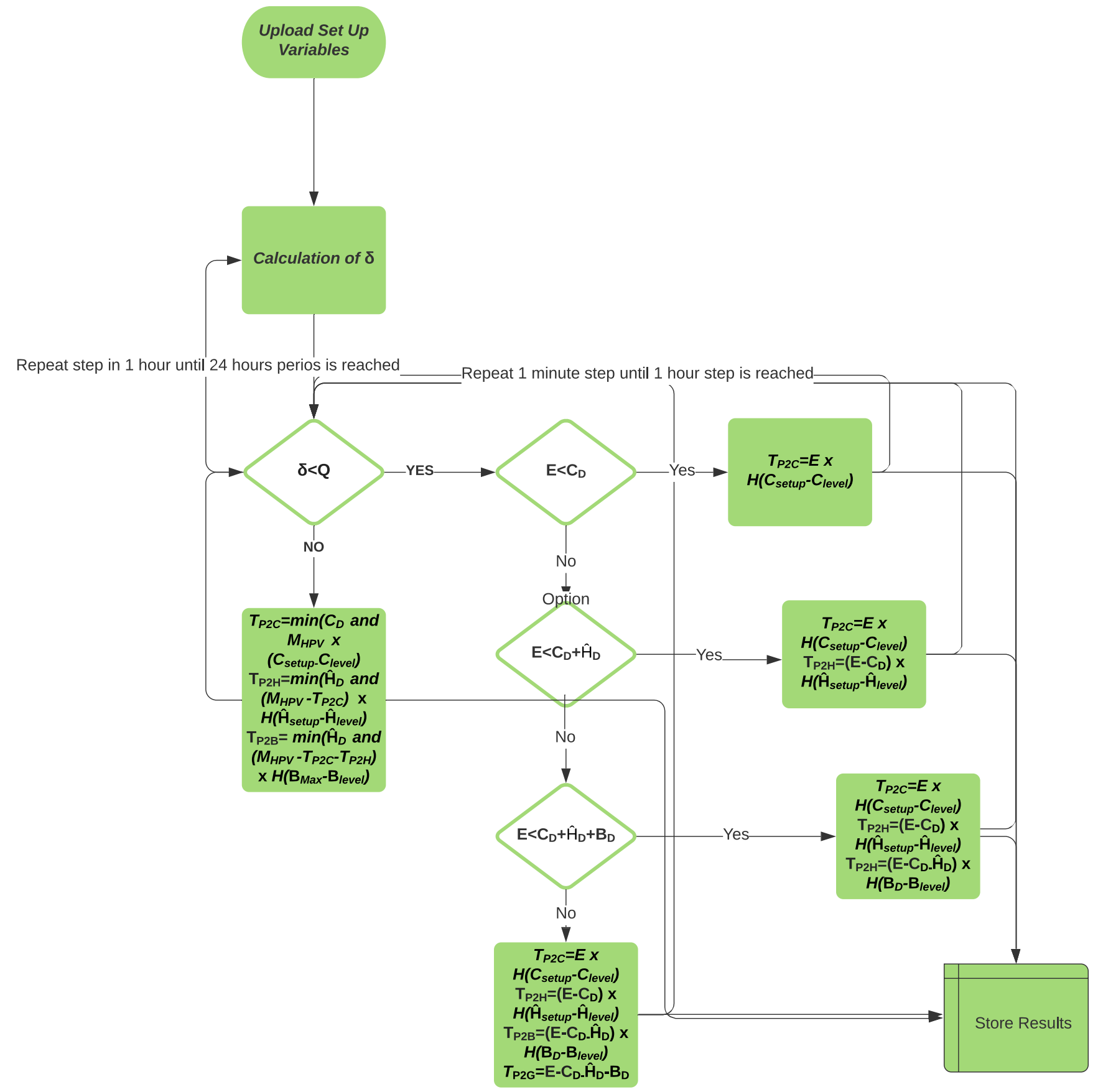

Figure A.10: 24 hours RED WoLF algorithm flowchart 